East African Medical Journal Vol. 77 No. 12 December 2000

SELF-PERCEIVED HEALTH AND METABOLIC CONTROL IN TANZANIAN DIABETIC PATIENTS

B. Smide, RN, PhD, Uppsala University, Department of Public Health and Caring Sciences, Döbelnsgatan 2, SE-752 37 Uppsala, Sweden and K. Wikblad, PhD, Uppsala

University, Department of Health and Caring Sciences, Uppsala Science Park, SE-75183 Uppsala, Sweden

Request for reprints to: B. Smide, Uppsala University, Department of Public Health and Caring Sciences, Döbelnsgatan 2 SE-752 37 Uppsala, Sweden.

\title{
SELF-PERCEIVED HEALTH AND METABOLIC CONTROL IN TANZANIAN DIABETIC PATIENTS
}

\author{
B. SMIDE and K. WIKBLAD
}

\begin{abstract}
Objectives: To analyse self-perceived health and metabolic control over a two-year period in a group of urban adult diabetic patients in Dar es Salaam, Tanzania.

Design: A longitudinal study with cross-sectional measurements of metabolic control and self-perceived health.

Setting: The study was carried out at the diabetes out-patient clinic of Muhimbili Medical Centre and at three district hospitals in the Dar es Salaam area in Tanzania.

Subjects: In 1995, one hundred and fifty consecutive diabetic patients (M/F:78/72) were seen. A re-organisation of the diabetes care was done in 1996. Due to difficulties in tracing the patients after the re-organisation, $50.4 \%$ of them were re-assessed in 1997.

Main outcome measures: The Swahili version of SF-36 health questionnaire was used to assess health. $\mathrm{HbA}_{1 \mathrm{c}}$ and fasting blood-glucose were used to evaluate metabolic control. Results: In patients assessed both in 1995 and 1997 significant improvements were found in the social and emotional functioning health domains. The mean $\mathrm{HbA}_{1 \mathrm{c}}$ valuewas significantly improved after the two years $(9.3 \pm 3.2 \%$ in 1995 versus $7.5 \pm 2.8 \%)$. Significant negative correlations were found between metabolic control and the health domains bodily pain, general health and vitality.

Conclusions: The study has highlighted the difficulties in performing follow up studies and it is most important to put lot of effort in informing patients prior to re-organisation of the care. Furthermore, our findings have shown that Tanzanian diabetic patients had improved their self-perceived health in social and emotional functioning and they had an improved metabolic control over the two-year period indicating an improved diabetes care.
\end{abstract}

\section{INTRODUCTION}

Several studies performed in high-income countries have reported the relationship between self-perceived health and metabolic control(1-4), while studies from low-income countries in Africa are rare. Only one study from Sudan was found reporting about self-perceived health and metabolic control in Type I diabetic patients(5).

In spite of many problems in delivering diabetes care in African countries, "good quality of life" should be a goal of good diabetes care(6). We have previously tested the Swahili version of SF-36 questionnaire in 518 diabetic patients attending the out-patient diabetes clinic at Muhimbili Medical Centre (MMC) in Dar es Salaam. The diabetic patients were found to have poorer self-perceived health than the general urban population in the same area(7).

The aim of the current study was to analyse the diabetic patients' self-perceived health and metabolic control over a two-year period, in Dar es Salaam, Tanzania.

\section{MATERIALS AND METHODS}

Re-organisation of diabetes care in Dar es Salaam: Most urban diabetic patients living in the Dar es Salaam area were in 1995 registered at the diabetes outpatient clinic at Muhimbili
Medical Centre (MMC). The patients were to come to the clinic every third month for check-ups. Children, pregnant women and those with severe hyperglycaemia attended the clinic more frequently. During 1995, insulin and anti-diabetic drugs were not always available at the clinic.

In 1996 a re-organisation of the diabetes care was done as there were too many patients attending the MMC clinic. The goal was that the patients should have possibilities to attend a diabetes clinic closer to their abode and the staff should have more time to see the patients. Diabetes outpatient clinics were opened at the three district hospitals in Dar es Salaam area, Mwananyamala, Temeke and Ilala. The diabetes nurse specialist, who had cared for the patients, when they had attended the MMC clinic, visited all the three district hospitals and had special education about diabetes with the staff. Special diabetes education material like paper charts informing about the importance of physical exercises and diet were made locally by the diabetes staff at the district hospitals. Insulin and anti-diabetic drugs were now available to a greater extent than in 1995.

Subjects: One year prior to the re-organisation, the first data collection was done. During five clinic days over a five-week period, 209 diabetic patients attended the MMC diabetes clinic routinely. Among these, eight patients every hour were randomly approached; thus 162 patients were included in the study. Out of these, three patients had no time to wait for the investigation, six were younger than 18 years old, and three had filled in questionnaires incorrectly; thus 150 patients (M/F, 78/72) remained for the analyses. Their mean age was $45.6 \pm 13$ years, 
mean age at diagnosis was $40.3 \pm 12.5$ years and mean diabetes duration was $5.3 \pm 6.0$ years. Thirty five per-cent of the patients were on insulin treatment. The mean $\mathrm{HbA}_{1 \mathrm{c}}$ value was $9.4 \pm 3.2 \%$, mean fasting blood-glucose value was $12.0 \pm 5.9 \mathrm{mmol} / \mathrm{l}$ and mean body mass index (BMI) was 24.6 \pm 4.4 . Seventy one per cent of the patients had attended school for less than nine years. Self-reports on financial status showed that $12 \%$ reported having good economy, $69 \%$ neither good/nor poor and $19 \%$ reported poor financial status in 1995. found between the groups of patients registered at the four hospitals.

The present paper only reports data from the group of patients who participated both in 1995 and $1997(n=70)$.

Measures: The same measures were used in 1995 and in 1997.

Self-perceived health: The Swahili version of SF-36 was used, which is a generic standardised questionnaire measuring the respondents self-perceived health during the previous four

Table 1

Patients assessed in 1995 and those re-assessed in 1997 after the diabetes care re-organisation in 1996

\begin{tabular}{|c|c|c|c|c|}
\hline Hospital register & $\begin{array}{l}\text { Patients assessed } \\
\text { in } 1995\end{array}$ & $\begin{array}{l}\text { Eligible patients for } \\
\text { re-assessment in 1997* }\end{array}$ & $\begin{array}{c}\text { Re-assessed at } \\
\text { follow-up in } 1997\end{array}$ & Not re-assessed \\
\hline Muhimbili Medical Centre (MMC) & 150 & 46 & 42 & 4 \\
\hline Mwananyamala & - & 19 & 10 & 9 \\
\hline Temeke & - & 24 & 8 & 16 \\
\hline Ilala & - & 20 & 10 & 10 \\
\hline $\begin{array}{l}\text { Not registered at any of } \\
\text { the four hospitals after the }\end{array}$ & & & & \\
\hline re-organisation & - & 30 & - & 30 \\
\hline Total & 150 & 139 & 70 & 69 \\
\hline
\end{tabular}

*eight patients had died and three had moved out of the area since the data collection in 1995

The second data collection was done one year after the reorganisation. It was planned to examine those patients who were seen in 1995. Prior to the 1997 data collection all medical records regarding the eligible patients were scrutinised. It was then found that out of the 150 diabetic patients seen in 1995, eight patients were reported to have died and three had moved away from the Dar es Salaam area, resulting in 139 eligible patients.

Out of the 139 eligible persons, 46 patients were still registered at the out-patient clinic at MMC in 1997. The remaining 93 patients were presumed to be registered at the three district hospitals. Thirty $(21.6 \%)$ of the eligible patients were not found in any of the hospital registers at the three outpatient clinics mentioned above, and 39 (28\%) were registered but did not turn up for the re-assessment at all. This meant that out of 139 eligible patients $70(50.4 \%)$ were re-assessed in 1997 (Table 1).

The missing 69 patients were traced for another year to explore what had happened to them. Registers and records, both at MMC, and at the three district hospitals, were repeatedly checked in order to find out an explanation why the patients had not registered after the reorganisation and returned for the follow up study. It was found that two of the 69 patients had visited the diabetes clinic in autumn 1997, and another seven in 1998. The remaining 60 patients had not attended the diabetes clinics at all after the reorganisation in 1996. No reasons were found to explain failure of follow up attendance.

Demographic and diabetes-related data collected in 1995, in the group of eligible patients who were examined once $(n=69)$, and those who were re-assessed after two years $(n=70)$ are presented in Table 2. Those eleven patients who were not available for the re-assessment (eight had died, and three had moved away from Dar es Salaam) were excluded in this comparison between the two groups. Among those patients who did not return for the follow up study, $23 \%$ were on insulin treatment and $77 \%$ were on diet or oral anti-diabetic drugs. Among those who came for the follow up study $44 \%$ were on insulin and $56 \%$ on diet or oral anti-diabetic drugs. No other significant differences were found between the two groups. Similarly, no significant differences in the above variables were
Table 2

Demographic and diabetes-related data in diabetic patients in 1995, in the group of eligible patients who did not come for the follow-up study $(n=69)$ and the group of patients who were followed for two years $(n=70)$. Patients not avaialble $(n=11)$ for the follow-up study were excluded in this comparison

\begin{tabular}{|c|c|c|}
\hline Variable & $\begin{array}{l}\text { Group examined } \\
\text { once }(n=69)\end{array}$ & $\begin{array}{r}\text { Group examined } \\
\text { twice }(n=70)\end{array}$ \\
\hline \multicolumn{3}{|l|}{ Sex } \\
\hline Male & 36 & 37 \\
\hline Female & 33 & 33 \\
\hline \multicolumn{3}{|l|}{ Age } \\
\hline years (mean \pm SD & $46.4 \pm 12.6$ & $45.0 \pm 12.2$ \\
\hline \multicolumn{3}{|l|}{ Age at diagnosis } \\
\hline years $($ mean $\pm \mathrm{SD})$ & $42.2 \pm 12.1$ & $39.2 \pm 11.5$ \\
\hline \multicolumn{3}{|l|}{ Diabetes duration } \\
\hline years $($ mean $\pm \mathrm{SD})$ & $4.2 \pm 5.8$ & $6.0 \pm 5.6$ \\
\hline \multicolumn{3}{|l|}{ Diabetes treatment } \\
\hline on insulin treatment & 16 & 31 \\
\hline on diet/oral antidiabetic drugs & $53 * *$ & 39 \\
\hline \multicolumn{3}{|l|}{$\mathrm{HbA}_{1 \mathrm{c}} \%$} \\
\hline \multicolumn{3}{|l|}{ Blood glucose (mmol/l) } \\
\hline $\begin{array}{l}\text { Body mass index }\left(\mathrm{kg} / \mathrm{m}^{2}\right) \\
(\text { mean } \pm \mathrm{SD})\end{array}$ & $25.2 \pm 4.0$ & $24.5 \pm 4.6$ \\
\hline \multicolumn{3}{|l|}{ Education years } \\
\hline \multicolumn{3}{|l|}{ Financial status 1} \\
\hline Good & 10 & 7 \\
\hline Neither/Nor & 47 & 47 \\
\hline Poor & 10 & 11 \\
\hline
\end{tabular}

$* * \mathrm{P}<0.01 ;{ }^{1}$ data missing in seven patients

weeks(7). It consists of 36 items grouped into eight health domains. The translation-back-translation between American English and Swahili was completed in 1993, following the recommendations in the SF-36 Manual(8). The aim of the translation was to preserve the conceptual equivalence while making the translation culturally relevant. The eight SF-36 health domains are: physical functioning 
(PF); role physical (RP); bodily pain (BP); general health $(\mathrm{GH})$; vitality (VT); social functioning (SF); role emotional (RE), and mental health (MH). For each SF-36 health domain, variable item scores were coded, summed, and transformed to a scale from 0 (worst health state) to the maximum score 100 (best health state) in accordance with the instructions in the SF-36 Manual(8). Cronbach's $\alpha$-coefficients for the different scalesranged from 0.67 to 0.92 in 1995 and from 0.69 to 0.90 in $1997(8,9)$.

Metabolic control: a) Glycosylated haemoglobin $\left(\mathrm{HbA}_{1 \mathrm{c}}\right)$ was measured in capillary blood using filter papers $\left(\mathrm{HbA}_{1 \mathrm{C}}\right.$ via Post ${ }^{\circledR}$, Boehringer-Mannheim Scandinavia AB). These test samples were kept in a deep freeze and, at the end of each data collection period, brought to Sweden, for analyses by ion exchange chromatography (mono $\mathrm{S}$, high performance liquid chromatography) $(10,11)$. The normal reference interval for the method is $3.8-5.2 \%$.

b) Glycaemic control: A portable glucometer (Glucometer II®, Boehringer-Mannheim, Germany) was used to test the fasting blood-glucose values. As the tests were performed before the introduction of new WHO-diagnosis criteria, $<6.7 \mathrm{mmol}$ per litre was considered the normal reference value (12).

Data about diabetes treatment (patients on insulin or on diet/oral anti-diabetic drugs) and diabetes duration were collected during the interviews. Body mass index (BMI) was calculated as body weight $(\mathrm{kg})$ with indoor clothing divided by height $\left(\mathrm{m}^{2}\right)$ without shoes. Additional data concerning sex, age, age at onset, education and patients' self-reports on financial status were collected.

Procedure: The data were collected in the same way in 1995 and 1997. Tanzanian student nurses and nurse teachers, all fluent in both Swahili and English, were specially trained to do structured interviews. The instructions in the SF-36 Manual were followed(8). The Tanzanian diabetes specialist nurse in charge of the clinic informed the patients about the study. After informed consent, the student nurses and nurse teachers assisted the diabetic patients to fill in the questionnaire, whereas to illiterate patients the questions were read out and the interviewers filled in the patients answers. The interviews took place in the waiting area of the diabetes clinic.

Prior to the re-assessment in 1997, all eligible patients were informed via an advertisement in the Swahili daily paper, announcements in the radio and name-lists on the notice-board at each clinic. All the eligible patients' names $(n=139)$ were announced, and the patients were requested to attend the applicable clinic according to the schedule mentioned. This procedure was chosen due to the absence of patients addresses, telephones or other means of contacts.

The medical research committee at MMC in Dar es Salaam, approved the study design.

Analysis and statistics: Results are presented as means \pm SD Paired t-tests were used for two group comparisons on interval level. For more than two group comparisons, analysis of variance (ANOVA) repeated measure was used. When calculating the selfperceived health over the two-year period the effect size was used which is the quotient between the difference and the weighted standard deviation $(8,13)$. Cronbach's alpha coefficient was used to calculate the internal consistency(9). Pearson's correlation coefficient was used to calculate the correlation between $\mathrm{HbA}_{1 \mathrm{C}}$ value and the SF-36 eight health domains. $\chi 2$ test was used for nominal data comparisons. We considered differences significant at $p<0.05$. Concerning glycosylated haemoglobin the patients were arbitrarily classified into three groups; $\mathrm{HbA}_{1 \mathrm{c}}$ values $\leq 7.5 \%$ were regarded as acceptable metabolic control, 7.6-9.9\% as unsatisfactory, and $\geq 10 \%$ as poor metabolic control.
Diabetes treatment was classified into two groups: those on insulin treatment and diet/oral anti-diabetic drugs. Education was categorised into two groups: those with $<9$ years and $\geq 9$ years schooling. The five-point scale asking about the patients' self-perceived financial status was transformed so that those reporting "very good" or "good" made up one group, "neither/ nor good" remained as one group and those reporting "poor" or "very poor" made up the group "poor financial status".

\section{RESULTS}

In 1995 one hundred and fifty diabetic patients were included in the data collection at MMC. After the reorganisation of the diabetes care at MMC in 1996, approximately $30 \%$ of the eligible patients were still registered there. Almost all of them (42 out of 46 patients) were re-examined after two years. At Mwananyamala district hospital 10 out of the 19 eligible patients were reassessed, while 8 out of 24 at Temeke and 10 out of 20 eligible patients at Ilala attended the diabetes clinics at each hospital respectively for follow up.

Self-perceived health: Over the two-year period the diabetic patients reported significantly improved selfperceived health in the health domain social functioning (mean 64.8 \pm 23.0 in 1995 versus $72.7 \pm 26.2$ in 1997 ; $\mathrm{t}=2.3$; $\mathrm{df}=69 ; \mathrm{p}=0.02$ ), indicating that after the two years they felt that physical and emotional problems interfered less with their social activities. Significant improvement was also reported in the health domain role emotional (mean $48.6 \pm 38.8$ in 1995 versus $66.7 \pm 39.7$ in $1997 ; \mathrm{t}=3.1 ; \mathrm{df}=69$; $\mathrm{p}=0.002$ ), meaning that after the two years the patients experienced fewer problems with work or other daily activities due to emotional problems. Small effect sizes were also found in the health domains role physical and vitality, thus indicating an improved self-perceived health within these domains (Table 3).

Table 3

Mean values $( \pm S D)$ and effect size for $S F-36$ health domains in diabetic patients measured in 1995 and 1997

\begin{tabular}{lcccc}
\hline $\begin{array}{l}\text { SF-36 health } \\
\text { domains }\end{array}$ & 1995 & 1997 & $\begin{array}{c}\text { Mean } \\
\text { difference } \\
1995 \text { to } 1997\end{array}$ & $\begin{array}{c}\text { Effect } \\
\text { size }\end{array}$ \\
\hline PF & $\mathrm{n}=70$ & $\mathrm{n}=70$ & 1.7 & 0.07 \\
RP & $78.1 \pm 23.0$ & $76.4 \pm 23.3$ & -10.7 & $0.26 \#$ \\
BP & $49.6 \pm 39.4$ & $60.4 \pm 44.1$ & -4.5 & 0.13 \\
GH & $53.2 \pm 28.0$ & $57.0 \pm 29.9$ & 1.3 & 0.05 \\
VT & $49.7 \pm 20.4$ & $48.7 \pm 19.3$ & -5.5 & $0.27 \#$ \\
SF & $55.5 \pm 20.4$ & $61.0 \pm 19.9$ & $-7.9 *$ & $0.32 \#$ \\
RE & $64.8 \pm 23.0$ & $72.7 \pm 26.2$ & $-18.1 * *$ & $0.46 \# \#$ \\
MH & $48.6 \pm 38.8$ & $66.7 \pm 39.7$ & -4.0 & 0.15 \\
& $65.9 \pm 19.3$ & $68.9 \pm 19.5$ & & \\
\hline
\end{tabular}

All scales 0-100. A high score indicates better health

Significance levels: $* \mathrm{P}<0.05 ; * * \mathrm{P}<0.01$

Effect size: \#=small $(\geq 0.2-<0.4)$, \#\#=moderate $(\geq 0.4-<0.8)$ 
In 1995 patients reporting poor financial status $(n=11)$ had significantly poorer health than those with neither poor/nor good $(n=47)$ in the general health domain (mean $35.4 \pm 19.2$ vs. $52.7 \pm 19.7 ; F=3.3 ; \mathrm{df}=2 / 60 ; \mathrm{p}=0.04$ ), while at the follow up study in 1997 no significant differences were found concerning financial status. Besides, patients on insulin treatment in $1995(\mathrm{n}=31)$ also perceived poorer health in the general health domain than those on diet/ antidiabetic oral treatment (mean $42.9 \pm 18.9$ vs. $54.6 \pm 20.8$; $\mathrm{t}=2.4 ; \mathrm{df}=66 ; \mathrm{p}=0.02$ ). At the follow up study in 1997 , however, no significant differences were found between different treatment groups.

Metabolic control: The mean $\mathrm{HbA}_{1 \mathrm{c}}$ value in the whole patient group $(n=70)$ was significantly improved after two years (mean value $9.3 \pm 3.2 \%$, min 4.8 max. 19.6 in 1995 versus $7.5 \pm 2.8 \%$, min 3.1 max. 15.4 in 1997 ; $\mathrm{t}=4.5 ; \mathrm{df}=62 ; \mathrm{p}=<0.0001$ ), while no significant differences were found in fasting blood glucose values, or between patients on insulin treatment or on diet/oral anti-diabetic drugs (Table 4).

\section{Table 4}

Diabetes-related variables in the same group of diabetic patients examined in 1995 and $1997(n=70)$ ( $H b A_{1 C}$ values in five patients missing)

\begin{tabular}{|c|c|c|c|}
\hline Variable & $\begin{array}{l}1995 \\
\mathrm{n}=70\end{array}$ & $\begin{array}{l}1997 \\
\mathrm{n}=70\end{array}$ & Statistics \\
\hline \multicolumn{4}{|l|}{$\mathrm{HbA}_{1 \mathrm{c}} \%$} \\
\hline Mean \pm SD & $9.3 \pm 3.2$ & $7.5 \pm 2.8$ & $\mathrm{p}=<0.0001$ \\
\hline Good control $(\%)$ & 34 & 59 & $\mathrm{~ns}$ \\
\hline Unsatisfactory control (\%) & 32 & 22 & \\
\hline Poor control $(\%)$ & 34 & 19 & \\
\hline \multicolumn{4}{|l|}{ Blood-glucose mmol/l } \\
\hline Mean \pm SD & $11.9 \pm 6.1$ & $11.5 \pm 6.2$ & ns \\
\hline \multicolumn{4}{|l|}{ Diabetes treatment } \\
\hline $\begin{array}{l}\text { On insulin treatment }(\%) \\
\text { On diet/oral } \\
\text { anti-diabetic drugs }(\%)\end{array}$ & 44 & 46 & ns \\
\hline
\end{tabular}

$\mathrm{ns}=$ not significant

Table 5

Number of patients with acceptable, unsatisfactory and poor metabolic control, based on HbA1c values, measured in 1995 and 1997

\begin{tabular}{lllll}
\hline & \multicolumn{4}{c}{ Metabolic control in 1995 } \\
& & $\begin{array}{l}\text { Acceptable } \\
<7.5 \%\end{array}$ & Unsatisfactory & Poor \\
& & $7.5-9.9 \%$ & $\geq 10 \%$ \\
\hline $\begin{array}{l}\text { Metabolic } \\
\text { control }\end{array}$ & $\begin{array}{l}\text { Acceptable } \\
<7.5 \%\end{array}$ & 15 & $14^{\mathrm{a}}$ & $10^{\mathrm{a}}$ \\
$\begin{array}{l}\text { in } \\
1997\end{array}$ & $\begin{array}{l}\text { Unsatisfactory } \\
7.5-9.9 \%\end{array}$ & $5^{\mathrm{b}}$ & 4 & $7^{\mathrm{a}}$ \\
& $\begin{array}{l}\text { Poor } \\
\geq 10 \%\end{array}$ & $2^{\mathrm{b}}$ & $4^{\mathrm{b}}$ & 4 \\
\hline
\end{tabular}

a Patients with improved metabolic control $(n=31)$

b Patients with deteriorated metabolic control $(n=11)$

The metabolic control was unchanged but acceptable in both 1995 and 1997 in $23.1 \%$, of the patients; unchanged but unsatisfactory/poor in $12.3 \%$; improved in $47.7 \%$, of the patients, but deteriorated in $16.9 \%$ (Table 5).
Correlation between metabolic control and selfperceived health: Significant negative correlations were found between the $\mathrm{HbA}_{1 \mathrm{c}}$ values and the health domains bodily pain $(r=-0.32, p=0.01)$, general health $(r=-0.27$, $\mathrm{p}=0.03)$ and vitality $(\mathrm{r}=-0.31, \mathrm{p}=0.01)$ indicating that patients with poor metabolic control experienced deteriorated health in these aspects.

\section{DISCUSSION}

The aim of the current study was to analyse the included diabetic patients' self- perceived health and metabolic control over a two-year period. Unfortunately, many patients did not return for the follow up assessment in 1997. All in all, the reason why almost all eligible patients registered at MMC-clinic participated in the second assessment might be that they were used to go there regularly. Explanation for the overall low follow up rate might be that after the re- organisation of the MMC-clinic, patients found it disagreeable to attend the clinics where they were not used to the clinical routines. Another explanation might be that the patients were not reached by the announcements on the radio or in the daily Swahili newspaper. Some patients might have preferred to visit private clinics, newly opened, instead of coming to government clinics, although we have no evidence of this. The difficulties in tracing the patients might also be due to the fact that people in the urban area move to other places without informing the diabetic clinics of their forwarding addresses or abode(14). The difficulties in doing follow up studies and tracing patients were in line with the ten year follow up study done by Corrigan and Ahren in northern Tanzania(15).

The only significant difference between patients who were examined in 1995 only and those who were followedup in 1997 was the higher percentage of patients on insulin treatment in 1997. From discussions with the patients, it was obvious that the availability of anti-diabetic drugs was a common reason for the patients to attend diabetes out-patient clinics.

A main finding in the current study was that patients reported an improved self-perceived health and had an improved metabolic control over the two-year period. Significantly higher scores were found in the two health domains, social functioning and role emotional. This means that the patients experienced less interference with their social activities or work due to physical and emotional problems. Furthermore, small effect sizes in the vitality and role physical health domains indicated that the patients did not feel as tired or worn out in 1997, as they did in 1995. The improvement in the patients' self-perceived health could also be compared with the improvement in the metabolic control as $\mathrm{HbA}_{1}$ cvalues at the follow up study were significantly lower. We presume the patients improvement to be due to a better anti-diabetic drug availability at the time of the follow up study. This explanation could be supported by McLarty(16), who in 1995 wrote that the availability of drugs was the most crucial aspect of diabetes care in Tanzania. The lack of 
anti-diabetic drugs in Tanzania has also been mentioned by Deeb(17). An alternative explanation might be an increased awareness among the diabetes staff after the reorganisation enhancing the improvement of glycaemic control(5).

The significant negative correlation between metabolic control and the health domains bodily pain, general health and vitality indicated a relation between poor metabolic control and deteriorated self-perceived health. In studies from industrialised countries(1-4) such correlations have not been found. These studies reported lower $\mathrm{HbA}_{1 \mathrm{c}}$ values in their patients and maybe only very high blood glucose values could be detected by health measures.

Furthermore, patients on insulin treatment in 1995 reported poorer general health than those who were treated with oral/ anti-diabetic drugs. When assessed in 1997, these previously observed differences were found not to be significant. An explanation for these findings could be the presumed improved availability of insulin at the time of the follow up study.

Although the Tanzanian patients had improved their self-perceived health over the two-year period, they had poorer health than the general urban population living in the same area(18). Among the eight health domains, the patients reported poor health in the general health domain, both in 1995 and 1997. These findings were in accordance with our results in the previous study, one year prior to the current one, in which the patients showed poor health in the general health domain(7). The same pattern was also reported in the general urban population in Dar es Salaam(18) and in Type I diabetic patients in Sudan(5). The patients' progress concerning self-perceived health might, to some extent, be explained as an investigation effect, such as receiving extra attention from the researchers, or receiving opportunities to speak about their problems, or obtaining feed-back concerning the outcome of clinical measures.

Our findings have highlighted the difficulties in doing follow up studies. Furthermore, the results have shown that Tanzanian diabetic patients had improved both their metabolic control and self-perceived health during a twoyear period. Poor metabolic control was correlated with poorer general health and vitality and more bodily pain.

In clinical diabetes care, it is most important to put a lot of effort in informing patients prior to any re-organisation. Additionally, the use of validated healthmeasures gives valuable information about the patients' self-perceived health, which together with medical measures give a holistic view of the diabetic patient's situation. In addition, the Tanzanian health authorities has a major role in supplying insulin to diabetic patients, as it is of utmost importance that they continuously get the lifesaving drug, insulin, in order to maintain a good metabolic control and a good self-perceived health.

\section{ACKNOWLEDGEMENTS}

This study was made possible by the assistance of Professor A B M Swai, in charge of post-graduate studies at MMC; Dr F Mugusi, our counterpart at MMC; Mrs Kessi, diabetes nurse specialist at MMC; Mrs Msoka and Mrs Lukwale, nurse teachers at the MMC; Dr A Kasebele, MMC; staff at the district hospitals in Mwananyamala, Ilala and Temeke; student nurses participating in the data-collection; all diabetic patients who so willingly participated in the studies; Lieke Felten, Nordic Clinic in Dar es Salaam, who assisted in the data collection implementation; Anita Bergström, Swedish diabetes nurse specialist, for travelling with us to Tanzania to participate in the data-collection; Special thanks also go to Boliden Contech for transport within Dar es Salaam. The study was supported by grants from Swedish Foundation for Health Caring Sciences and Allergy Research, Swedish Red Cross School of Nursing, Lions, Bayer Ames and Boehringer-Mannheim, Scandinavia AB.

\section{REFERENCES}

1. Diabetes Control and Complication Trial Research Group (DCCT). Influence of Intensive Diabetes Treatment on Quality-of-Life Outcomes in the Diabetes Control and Complications Trial. Diabetes Care. 1996; 19:195-203.

2. Wandell, PE., Brorsson, B. and Aberg, H. Quality of life in diabetic patients registered with primary health care services in Sweden. Scand. J. Primary Hlth Care. 1997; 15:97-102.

3. Wikblad, K., Leksell, J. and Wibell, L. Health-related quality of life in relation to metabolic control and late complications in patients with insulin dependent diabetes mellitus. Quality of Life Research. 1996; 5:123-130.

4. Goddijn, P.P.M., Bilo, H.J.G., Feskens, E.J.M., Groniert, K.H., van der Zee, K.I. and Meyboom-de Jong, B. Longitudinal study on glycaemic control and quality of life in patients with Type 2 diabetes mellitus referred for intensified control. Diabet. Med. 1999; 16:23-30.

5. Elbagir, M. Epidemiology and Clinical Course of Adult Diabetes Mellitus in Sudan. Thesis, Uppsala University, Sweden, 1997.

6. Gill, G.V. Delivery of diabetes care. In: Gill G, ed. Diabetes in Africa. Cambridge: FSG Communications, 1997:

7. Smide, B., Whiting, D., Mugusi, F., Felten, L. and Wikblad, K. Self-perceived health in urban diabetic patients in Tanzania. East Afr. Med. J. 1999; 76:67-70.

8. Ware, J., Snow, K., Kosinski, M., and Gandek, B. SF-36 Health Survey Manual and Interpretation Guide. Boston: The Health Institute, New England Medical Centre, 1993.

9. Polit, D. and Hungler, B. Nursing research. Principles and methods. Philadelphia: J B Lippincott Company, 1995.

10. Wikblad, K., Smide, B., Bergstrom, A., Wahren, L., Mugusi, F. and Jeppsson, JO. Immediate assessment of $\mathrm{HbA}_{1 \mathrm{c}}$ under field conditions in Tanzania. Diabetes Research and Clinical Practice. 1998; 40:123-128.

11. Jeppsson, J., Jerntorp, P., Almer, L., Persson, R., Ekberg, G. and Sundkvist, G. Capillary blood on filter paper for determination of $\mathrm{HbA}_{1 \mathrm{c}}$ by ion exchange chromatography. Diabetes Care. 1996; 19:142-145.

12. World Health Organisation Expert Committee. Diabetes Mellitus. Technical Report series NR 742. Geneve 1985.

13. Kazis, L., Anderson, J. and Meenan, R. Effect sizes for interpreting changes in health status. Medical Care. 1989; 27:178 -189.

14. McLarty D., Pollitt, C. and A.B.M. Swai. Diabetes in Africa. Diab. Med. 1990; 7:670-684.

15. Corrigan, C. and Ahren, B. Ten years experience of a diabetes clinic in Northern Tanzania. East Afr. Med. J. 1987; 64: 772-780.

16. McLarty, D. Some aspects of diabetes in Tanzania. Diabetes Reviews International. 1995; 3:6-9.

17. Deeb, LC., Tan, MH. and Alberti, K. Insulin availability among International Diabetes Federation member associations. Report of the Task Force on Insulin Distribution. Diabetes Care. 1994; 17:220-223.

18. Whiting, D. Policy implications of Adult Morbidity and Mortality Project - end of phase 1 report. Muhimbili Medical Centre, Dar es Salaam, Tanzania, 1997. 